This is an Accepted Manuscript of an article published by Taylor \& Francis in International Journal of Disability, Development and Education on 2017/13/07, available online :

https://www.tandfonline.com/doi/abs/10.1080/1034912X.2017.1346236?journalCode=cijd20.

\title{
Effects of a Mindfulness-Based Intervention on the Perception of Basic Psychological Need Satisfaction among Special Education Students
}

\author{
Catherine Malboeuf-Hurtubise ${ }^{a, b^{*}}$, Mireille Joussemetc, Geneviève Taylor ${ }^{b, d}$, \\ and Eric Lacourse \\ aDepartment of Educational Sciences, Université du Québec en Outaouais, \\ Gatineau, Québec, Canada; 'besearch Unit on Mindfulness; ${ }^{c}$ Department of \\ Psychology, Université de Montréal, Montréal, Québec, Canada; and Research \\ Unit on Children's Psychosocial Maladjustment, Montreal, Québec, Canada; \\ dDepartment of Education and Pedagogy, Université du Québec à Montréal, \\ Montréal, Québec Canada; eDepartment of Sociology/School of Criminology, \\ Université de Montréal, Montréal, Québec, Canada
}

Mindfulness-Based Interventions (MBIs) have been increasingly implemented in schools to foster better emotional regulation skills for students with special education needs such as learning disabilities (LDs). This pilot study aimed to evaluate the impact of a MBI on the need satisfaction of elementary students with severe LDs. A prospective quasi-experimental design involving one group and two time points was employed. A sample of 14 elementary school students from a severe LDs special education class participated in this project. Repeated-measures ANOVAs were conducted and revealed a significant reduction in need satisfaction, with a large effect size $\left(\eta^{2}=0.35\right)$. Contrary to our hypothesis, the MBI appeared to be negatively related to need satisfaction among participants. These results indicate that MBIs could be linked with better self-evaluation skills in students with severe learning disabilities, which, in turn, may change (or increase the accuracy of) the perception that children have of their own need satisfaction.

\footnotetext{
* Corresponding Author. Email: catherine.malboeuf-hurtubise@uqo.ca
} 
Keywords: autonomy; competence; mindfulness-based meditation; need satisfaction; relatedness; school psychology; self-determination theory; severe learning disabilities

\section{Introduction}

Approximately one in 20 students in the United States have a learning disability, characterised by significant difficulties in reading, writing and mathematics (National Center for Education Statistics, 2014). Symptoms of psychological distress and poor emotional regulation skills are often observed in these children, impacting not only school engagement and overall academic success but also decision-making skills and psychological and social functioning at home and in school (American Psychiatric Association, 2013; Bauminger \& Kimhi-Kind, 2008). Conversely, students with LDs who do not present emotional regulation deficits often have better social functioning and decision making skills, highlighting the need for interventions specifically targeting emotional regulation in these students. Another difficulty that students with LDs often encounter is that teachers tend to be more controlling with them than with other students, resulting in lower perceived competence and a lack of perceived personal control (Grolnick \& Ryan, 1990). Studies have shown that feeling autonomous, competent and related to others is just as important for LD students than other students, and the satisfaction of these needs predicts their academic achievement and psychological adjustment (Carter, Lane, Pierson, \& Glaeser, 2006; Deci, Hodges, Pierson, \& Tomassone, 1992).

There is a paucity of skills-based interventions targeting the alleviation of psychosocial problems among children with LDs. One study by Kam and colleagues (2004) showed that an intervention promoting emotional development, self-regulation and social skills was useful in decreasing both internalised and externalised behaviors and depressive symptoms for students in special education classes. However, the sample in this study included students with a vast array 
of mental health, intellectual disability and LD issues. Thus, there is great need of research on interventions specifically tailored to children with LDs.

Mindfulness-Based Interventions (MBIs) have been increasingly implemented in schools to foster better emotional regulation skills for students with special education needs. Preliminary evidence suggests that these interventions hold promise in reducing the burden of LDs, especially regarding reduced anxiety and depression, and increased attention (Malboeuf-Hurtubise, Joussemet, Douaire, \& Lacourse, 2015; Taylor \& Malboeuf-Hurtubise, 2016; Zenner, Herrnleben-Kurz, \& Walach, 2013). To date, one study reported results of a MBI with adolescents with LDs and suggested that it could be useful to decrease anxiety and promote better social skills (Beauchemin, Hutchins, \& Patterson, 2008). However, MBIs have not yet been used with elementary school children with LDs in special education classes with the aim of increasing their basic psychological need satisfaction, and ultimately, their well-being.

Mindfulness can be defined as the process by which we "[...pay] attention in a particular way: on purpose, in the present moment, and nonjudgmentally" (Kabat-Zinn, 1994). According to Ryan and Deci (2000), mindfulness leads to optimal self-regulation, allowing individuals to be in touch with their needs, values and emotions (Brown \& Ryan, 2003; Ryan \& Deci, 2000). As such, mindfulness is hypothesised to lead to more realistic appraisals (and, ultimately, better satisfaction) of the three basic psychological needs for: competence (i.e. feeling effective in one's interactions with the environment), autonomy (i.e. feeling choice, volition and willingness in one's actions), and relatedness (i.e. feeling connected with and loved by others) (Deci, Ryan, Schultz, \& Niemiec, 2015). An increasing amount of research has supported this proposition (Brown \& Kasser, 2005; Brown, Ryan, \& Creswell, 2007; Levesque \& Brown, 2007). However, all of these studies measured mindfulness as a stable individual difference rather than as an acquired ability and have all been conducted with adults. 


\section{C. Malboeuf-Hurtubise et al.}

Self-determination theory (SDT) (Ryan \& Deci, 2000), a macrotheory of human motivation and optimal functioning, posits that the degree to which the three basic psychological needs are satisfied (vs. thwarted) relates to greater functioning and well-being (Deci \& Ryan, 2000). Since decades of research within the SDT framework have shown that such need satisfaction is positively related to school engagement, performance and persistence (Niemiec \& Ryan, 2009), even among students with a LD (Deci et al., 1992), it appears particularly relevant and important to explore how a mindfulness intervention could affect students' basic need satisfaction.

The goal of the present pilot study was to evaluate the feasibility and effect of an eightweek MBI on the perception of basic psycholgoical need satisfaction on elementary school students with severe LDs. We hypothesised that our MBI would influence how children perceive their level of competence, autonomy and relatedness satisfaction. Specifically, we hypothesised that our MBI would have a significant and positive effect on need satisfaction among these students, namely that they would feel more autonomous, competent and socially related pre-topost intervention.

\section{Method}

\section{Design and Participants}

A quasi-experimental one-group pretest-posttest design was used. One group quasi-experimental designs are often used in the context of pilot studies assessing the impact of a novel intervention in which control conditions are unavailable at the time of conducting the project (Spector, 1981; Thabane et al., 2010). Additionally, these designs are used when a limited pool of participants is available, as was the case of this pilot and feasibility study, which targeted only one LD special education class (Gravetter \& Forzano, 2011; Harris et al., 2006). This pilot study was conducted in collaboration with an elementary school in Montreal, Canada. Ethics approval was obtained 
from all institutions involved. A total of 14 elementary school students aged 9 to 12 years old in a LD special education class participated in this study. All participants matched the following criteria: they were experiencing persistent difficulties in reading, writing and mathematics and presented a delay of two academic years or more in all of these areas. Their IQ scores fell within the borderline range of intellectual functioning ( $70<$ IQ score $<79$ ), as shown by extensive evaluation of their cognitive abilities. Additionally, students in this class had to have been previously assessed by a psychologist and/or a speech-language pathologist. For the purposes of this study, participants had to be willing to participate in an eight-week mindfulness meditation program and be available to answer questionnaires at pre-test and at post-test. As this project was conducted in French, participants were required to speak and understand the language. There was no attrition during this pilot study; all students filled out pre and post-intervention questionnaires. Consent was obtained from all parents and students taking part in this study.

\section{Mindfulness-Based Intervention}

The intervention used in this study was adapted from previous work from the first author with children and adolescents in school and hospital settings (Malboeuf-Hurtubise et al., 2016; Malboeuf-Hurtubise, Lacourse, Taylor, Joussemet, \& Ben Amor, in press). The first author of this article, a trained therapist in MBI with previous experience with groups in pediatric oncology and school psychology, led the intervention and was assisted by the school social worker. The mindfulness-based intervention lasted eight weeks. The mindfulness group met once a week for 60 mins. The duration of each session was adapted to: (1) fit one daily classroom period, and (2) offer a developmentally appropriate intervention specifically targeted to match elementary school students' shorter attention span. Weekly sessions content can be found in Table 1. Homework 
was assigned every week, and practice was required at least once a week. These were completed during class time between sessions with the teacher. Guided meditations were recorded and a copy was given to the teacher for in-class practice.

\section{[t] Insert Table 1 near here/[t]}

The MBI was adapted to be developmentally appropriate for elementary school students. Mindfulness practices during sessions were varied (e.g. mindfulness in movement, mindfulness exercises with the five senses, walking meditation), and content was delivered in a concrete, explicit and playful manner. Examples provided by therapists during group discussions were developmentally appropriate and resonated with participants' daily experiences to foster connection and cohesion in the group.

\section{Measure}

Students filled out the pre and post-intervention questionnaire in class, with a research assistant who was present to any questions they might have.

\section{Need Satisfaction}

All participants rated how competent, autonomous, and related they felt in their everyday life, by filling a 29-item scale adapted from a scale used in a previous, similar study (Savard, Joussemet, Pelletier, \& Mageau, 2013). Children were asked to rate their agreement on a 7-point Likert scale (from $1=$ Strongly disagree to $7=$ Strongly agree) to items such as "In my everyday life ... I feel free to be myself" (autonomy); ... I am able to reach my goals (competence) and "In my relationship with others, I feel appreciated" (relatedness). Since autonomy, competence and relatedness scores are typically highly correlated, as they were in this study ( $r$ 's $>0.58)$, analyses were performed using first a composite need satisfaction score and subsequently decomposed 
using specific need satisfaction scores (Milyavskaya \& Koestner, 2011). Internal consistency was good in this sample $(\alpha=.81)$. Test-retest reliability was excellent in this sample $(r=.68)$.

\section{Results}

\section{Data Analysis}

Descriptive statistics were used for demographic data. Demographic data of participants are presented in Table 2.

\section{[t] Insert Table 2 near here/[t]}

Primary hypotheses were tested with repeated-measures ANOVAs, allowing within-subject comparisons of pre-to-post test data. $P$-values of $<.05$ were considered statistically significant. Effect sizes were computed using partial $\eta^{2}$, and were interpreted according to Cohen's (2013) proposed guidelines for social sciences, where values approaching 0.01 are considered a small effect, values approaching 0.06 are considered a moderate effect and values approaching 0.14 are considered a large effect.

\section{Statistical Power}

A priori statistical power analyses had been conducted using $\mathrm{G}^{*}$ Power software (Faul, Erdfelder, Lang, \& Buchner, 2007). In accordance with our planned analyses and the design of this project, aiming for a statistical power of .90 and for moderate effect sizes (Cohen's $f=.50)$, a sample size of 13 participants was required to ensure adequate statistical power. A sample of 14 participants took part in this project, ensuring that statistical power was adequate to detect statistically significant pre-to-post differences at the $p=.05$ threshold. 


\section{Within-Group Analyses}

A repeated-measures ANOVA was conducted to explore the impact of our MBI on children's perception of their need satisfaction (see Table 3 for details). Results revealed significant differences in levels of composite score of need satisfaction (Wilks' Lambda $=.65, F(1,13)=$ 6.85, $p=.02$, partial $\eta^{2}=.35$ ) from pre-to-post intervention. Post-hoc comparisons using a Bonferroni correction indicated that the mean need satisfaction score at pre-test $(\mathrm{M}=5.6 ; \mathrm{SD}=$ .31) was significantly different from the mean need satisfaction score at post-test $(\mathrm{M}=5.0 ; \mathrm{SD}=$ .27). Additionally, results revealed significant differences in levels of competence (Wilks' Lambda $=.66, F(1,13)=6.73, p=.02$, partial $\left.\eta^{2}=.34\right)$ from pre-to-post intervention. Post-hoc comparisons using a Bonferroni correction indicated that the mean need satisfaction score at pretest $(M=5.74 ; S D=1.35)$ was significantly different from the mean need satisfaction score at post-test $(M=4.76 ; S D=1.13)$. See Figures 1 to 4 for individual trajectories of the pre-to-post composite score of need satisfaction, and the autonomy, competence and relatedness scores.

\section{[f] Insert Figures 1 to 4 near here/[f]}

\section{[t] Insert Table 3 near here/[t]}

\section{Discussion}

This paper presents results from a MBI pilot study for elementary school children with severe LDs, schooled in a special education class, and its impact on their basic psychological need satisfaction. Contrary to our hypothesis, based on students' self-reports, our results indicate that the MBI led these children to report a slightly lower sense of basic psychological need fulfillment. This seems to be especially true in regards to students' perception of their competence need. 
According to SDT, mindfulness promotes awareness and acceptance of one's strengths and weaknesses (Deci et al., 2015). While prior research using longitudinal designs has shown a positive correlation between dispositional measures of mindfulness and need satisfaction (Brown \& Ryan, 2003; Brown et al., 2007), our results show a reversed association between these two concepts. This could be explained by the fact that the present study evaluated the impact of a MBI on intra-individual rather than inter-individual differences (i.e. skill vs. dispositional measure, within vs. between-group). As these children with severe LDs became more mindful, they may have become more aware of their limitations in terms of academic and social skills. This may have had a direct impact on their perception of how autonomous, related, and especially competent, they felt. Indeed, SDT hypothesises that as individuals practice mindfulness, environmental barriers clouding one's evaluation of needs satisfaction (such as peer pressure or social desirability) fall, leading to heightened awareness, experience and perception of one's feelings and thoughts (Deci et al., 2015; Levesque \& Brown, 2007). Thus, results from this pilot study can be interpreted in light of the removal of such barriers, rendering participants more in tune with their internal processes and more aware of the controlling forces that were influencing them. In other words, it is possible that, as they became more mindful, students were able to describe their need satisfaction more clearly, without being influenced by their desire to please others and/or to see themselves in a certain way when responding to the questionnaire.

Results from this pilot study indicate that MBIs could be linked with improved selfevaluation skills in students with severe LDs, which, in turn, may change (or increase the accuracy of) the perception that children have of their own psychological need satisfaction. Past research has suggested that awareness of both positive and negative experiences and selfappraisals are crucial in constructing a more realistic sense of self, which leads to increased autonomous motivation and well-being later on (Weinstein, Deci, \& Ryan, 2011). Thus, need 
satisfaction in our participants may have decreased at post-intervention because of increased awareness of academic and social shortcomings. However, this renewed awareness may contribute to more autonomous goal setting, problem-solving and regulatory behaviors, which, in turn, may subsequently increase psychological need satisfaction in the long term.

Results from this pilot evaluated the mean change in participants. However, individual differences in trajectories tend to reveal a more complex picture in regards to the impact of the MBI on participants' basic psychological need satisfaction. As can be seen in Figure 1, a subgroup of participants (4/14) showed increases in need satisfaction over time, whereas a small number of participants (2/14) showed little change over time, and a majority of participants (8/14) showed a decline in need satisfaction, with one participant in particular showing a large decline. As such, individual variability of need satisfaction scores suggests that the MBI worked differently for different students. Anecdotal evidence seems to indicate that students who reported increases in need satisfaction pre-to-post intervention were perceived by their teacher as being more easily demoralized and more anxious at pre-intervention (as indicated by their verbalisations, e.g. "I am no good", "I suck in school”). These verbalisations could be indicative of how this subgroup of students perceived and defined themselves. For the most part, students from this subgroup reported significant increases in autonomy pre-to-post intervention. Thus, it could be possible that the MBI had a positive impact by fostering a renewed sense of confidence and assurance, which led to an increased perception of autonomous behavior. However, given the small sample size, the absence of a control group and of follow-up measures, caution is strongly warranted in interpreting results from a subgroup of this sample. Nonetheless, these results can provide clues onto variables that could be measured in subsequent designs, such as self-efficacy or self-compassion. 


\section{Strengths}

This study was the only study known to the authors attempting to measure the impact of a MBI on need satisfaction for children with special education needs. Thus, results from this pilot study offer some insight about the experience of children learning mindfulness, and points to selfdetermination theory research in a school setting for children with severe LDs. Additional strengths of this pilot study include the absence of attrition, a large effect size for statistically significant variables and the fact that this project is one of very few evaluating the impact of an MBI on elementary school students with special education needs.

\section{Limitations}

Limitations of this pilot study include the use of a one-group pretest-posttest design, a small sample and the absence of a follow-up measure. Given past research mentioned above, it is possible that a follow-up assessment would have revealed an increase in need satisfaction, stemming from a renewed awareness of their experiences, more autonomous goal-directed behaviors, and thus an elevated satisfaction of autonomy, competence, and relatedness in the long term. It is also possible, on the contrary, that a follow-up assessment would not have revealed such an improvement in need satisfaction, which could be indicative of potential harmful effects of the MBI to a subset of students with LDs. Although the literature has not reported adverse effects of mindfulness practice specifically in children with LDs, past research has suggested that individuals with panic disorder and post-traumatic stress disorder may be more vulnerable to experiencing negative effects of MBIs (Lustyk, Chawla, Nolan, \& Marlatt, 2009). Thus, identifying students with these disorders and excluding them from certain mindfulness activities (such as, for example, longer sitting and breathing meditations) is recommended. 


\section{C. Malboeuf-Hurtubise et al.}

Without a control group, observed changes in our participants might not be attributed to the mindfulness intervention alone. Potential threats to internal validity could be time-related factors, such as testing effects and regression to the mean, or demand characteristics. Moreover, to our knowledge, history was not a threat to internal validity in this pilot, as no event affecting the whole group of participants occurred during the mindfulness intervention. In light of these limitations, we cannot draw robust conclusions about the intervention's effect, as these may be an artifact of demand characteristics, measurement problems or passage of time. As such, it would be more appropriate to consider this study as a very early phase study, from which results tend to indicate that MBIs for students with severe LDs are feasible and promising (Craig et al., 2011; Dimidjian \& Segal, 2015).

\section{Recommendations for Future Studies}

The use of multiple baseline single case designs or randomised controlled trials is strongly recommended in future studies in order to replicate these results and conclude on their robustness (Malboeuf-Hurtubise, Lacourse, Joussemet, \& Ben Amor, 2015). With larger samples, further sensitivity analyses could also be performed (Thabane et al., 2013). Future studies would do well to track how the satisfaction of children's basic psychological needs evolves over time. Using a scale that measures both need satisfaction and need frustration is also recommended, in order to provide a more comprehensive portrait of these students' perception of their basic psychological needs (Chen et al., 2015). The impact of MBIs on basic psychological need satisfaction of students without LDs could also be evaluated in further research: if short-term declines in need satisfaction were observed, followed by increases at follow-up times, results could argue for a broader applicability of the intervention. Finally, future studies could evaluate the impact of 
integrating interventions fostering need satisfaction to MBIs in school settings, in order to help these students fulfill their basic psychological needs, in spite of their LDs.

\section{Acknowledgments}

The authors wish to thank Josée Douaire, Ph.D. and Danielle Rivest for their input on the project and assistance in its implementation. Funding for this project was provided by scholarships to the first author from the Fonds de Recherche en Société et Culture du Québec.

\section{Disclosure Statement}

Catherine Malboeuf-Hurtubise and Eric Lacourse have signed a contract with Midi Trente publishers to release a manual on the mindfulness-based intervention described and used in this study. Mireille Joussemet and Geneviève Taylor declare that they have no conflict of interest.

All procedures performed in studies involving human participants were in accordance with the ethical standards of the institutional and/or national research committee and with the 1964 Helsinki declaration and its later amendments or comparable ethical standards.

\section{References}

American Psychiatric Association. (2013). Diagnostic and statistical manual of mental disorders :DSM-5.

Bauminger, N., \& Kimhi-Kind, I. (2008). Social information processing, security of attachment, and emotion regulation in children with learning disabilities. Journal of Learning Disabilities, 41(4), 315-332.

Beauchemin, J., Hutchins, T. L., \& Patterson, F. (2008). Mindfulness Meditation May Lessen Anxiety, Promote Social Skills, and Improve Academic Performance Among Adolescents With Learning Disabilities. Complementary Health Practice Review, 13(1), 34-45. doi:10.1177/1533210107311624

Brown, K. W., \& Kasser, T. (2005). Are psychological and ecological well-being compatible? The role of values, mindfulness, and lifestyle. Social Indicators Research, 74(2), 349-368.

Brown, K. W., \& Ryan, R. M. (2003). The benefits of being present: mindfulness and its role in psychological well-being. Journal of personality and social psychology, 84(4), 822.

Brown, K. W., Ryan, R. M., \& Creswell, J. D. (2007). Mindfulness: Theoretical foundations and evidence for its salutary effects. Psychological inquiry, 18(4), 211-237. 
Carter, E. W., Lane, K. L., Pierson, M. R., \& Glaeser, B. (2006). Self-determination skills and opportunities of transition-age youth with emotional disturbance and learning disabilities.

Exceptional Children, 72(3), 333-346.

Chen, B., Vansteenkiste, M., Beyers, W., Boone, L., Deci, E. L., Van der Kaap-Deeder, J., . . . Mouratidis, A. (2015). Basic psychological need satisfaction, need frustration, and need strength across four cultures. Motivation and Emotion, 39(2), 216-236.

Cohen, J. (2013). Statistical power analysis for the behavioral sciences: Routledge Academic.

Craig, P., Dieppe, P., Macintyre, S., Michie, S., Nazareth, I., \& Petticrew, M. (2011). Developing and evaluating complex interventions. Medical Research Council, $U K$.

Deci, E. L., Hodges, R., Pierson, L., \& Tomassone, J. (1992). Autonomy and competence as motivational factors in students with learning disabilities and emotional handicaps. Journal of Learning Disabilities, 25(7), 457-471.

Deci, E. L., \& Ryan, R. M. (2000). The "what" and "why" of goal pursuits: Human needs and the self-determination of behavior. Psychological Inquiry, 11, 227-268.

https://doi.org/10.1207/S15327965PLI1104_01

Deci, E. L., Ryan, R. M., Schultz, P. P., \& Niemiec, C. P. (2015). Being aware and functioning fully. Handbook of Mindfulness: Theory, Research, and Practice, 112.

Dimidjian, S., \& Segal, Z. V. (2015). Prospects for a clinical science of mindfulness-based intervention. American psychologist, 70(7), 593.

Faul, F., Erdfelder, E., Lang, A.-G., \& Buchner, A. (2007). G* Power 3: A flexible statistical power analysis program for the social, behavioral, and biomedical sciences. Behavior research methods, 39(2), 175-191.

Gravetter, F., \& Forzano, L.-A. (2011). Research methods for the behavioral sciences: Cengage Learning.

Grolnick, W. S., \& Ryan, R. M. (1990). Self-Perceptions, Motivation, and Adjustment in Children with Learning Disabilities A Multiple Group Comparison Study. Journal of Learning Disabilities, 23(3), 177-184.

Harris, A. D., McGregor, J. C., Perencevich, E. N., Furuno, J. P., Zhu, J., Peterson, D. E., \& Finkelstein, J. (2006). The use and interpretation of quasi-experimental studies in medical informatics. Journal of the American Medical Informatics Association, 13(1), 16-23.

Kabat-Zinn, J. (1994). Wherever you go there you are: Minfulness meditation in everyday life. New York: Hyperion.

Kam, C.-M., Greenberg, M. T., \& Kusche, C. A. (2004). Sustained effects of the PATHS curriculum on the social and psychological adjustment of children in special education. Journal of emotional and behavioral disorders, 12(2), 66-78.

Levesque, C., \& Brown, K. W. (2007). Mindfulness as a moderator of the effect of implicit motivational self-concept on day-to-day behavioral motivation. Motivation and Emotion, 31(4), 284-299.

Lustyk, M., Chawla, N., Nolan, R., \& Marlatt, G. (2009). Mindfulness meditation research: Issues of participant screening, safety procedures, and researcher training. Advances in MindBody Medicine, 24(1), 20-30.

Malboeuf-Hurtubise, C., Achille, M., Muise, L., Beauregard-Lacroix, R., Vadnais, M., \& Lacourse, É. (2016). A mindfulness-based meditation pilot study: lessons learned on acceptability and feasibility in adolescents with cancer. Journal of Child and Family Studies, 25(4), 11681177. 
Malboeuf-Hurtubise, C., Joussemet, M., Douaire, J., \& Lacourse, E. (2015). Impact of a mindfulness-based pilot study on elementary students with severe learning difficulties. . Annual Conference of the National Association of School Psychologists.

Malboeuf-Hurtubise, C., Lacourse, É., Joussemet, M., \& Ben Amor, L. (2015). A mindfulnessbased intervention for elementary students with internalized disorders: A multiple single casestudy design. Paper presented at the 7th Annual Conference of Quantitative Methods and Humanities Montreal, Quebec.

Malboeuf-Hurtubise, C., Lacourse, É., Taylor, G., Joussemet, M., \& Ben Amor, L. (in press). A Mindfulness-Based Intervention Pilot Feasibility Study for Elementary School Students With Severe Learning Difficulties: Effects on Internalized and Externalized Symptoms From an Emotional Regulation Perspective. Journal of Evidence-Based Complementary and Alternative Medicine.

Milyavskaya, M., \& Koestner, R. (2011). Psychological needs, motivation, and well-being: A test of self-determination theory across multiple domains. Personality and Individual Differences, 50(3), 387-391.

National Center for Education Statistics. (2014). Fast Facts: Students with disabilities. Retrieved from http://nces.ed.gov/fastfacts/display.asp?id=64

Niemiec, C. P., \& Ryan, R. M. (2009). Autonomy, competence, and relatedness in the classroom Applying self-determination theory to educational practice. Theory and Research in Education, 7(2), 133-144.

Ryan, R. M., \& Deci, E. L. (2000). Self-determination theory and the facilitation of intrinsic motivation, social development, and well-being. American psychologist, 55(1), 68.

Savard, A., Joussemet, M., Pelletier, J. E., \& Mageau, G. A. (2013). The benefits of autonomy support for adolescents with severe emotional and behavioral problems. Motivation and Emotion, $1-13$.

Spector, P. E. (1981). Research designs: Sage.

Taylor, G., \& Malboeuf-Hurtubise, C. (2016). La présence attentive en milieu scolaire: État des connaissances et pistes de recherche pour l'avenir [Mindulness in school settings: Existing knowledge and recommendations for future research] . In S. Grégoire, L. Lachance, \& L. Richer (Eds.), La présence attentive (mindfulness): État des connaissances théoriques, empiriques et pratiques [Mindfulness: Theory, research and practice. Québec, Québec, Canada: Presses de l'Université du Québec.

Thabane, L., Ma, J., Chu, R., Cheng, J., Ismaila, A., Rios, L. P., . . Goldsmith, C. H. (2010). A tutorial on pilot studies: the what, why and how. BMC medical research methodology, 10(1), 1. Thabane, L., Mbuagbaw, L., Zhang, S., Samaan, Z., Marcucci, M., Ye, C., . . Kosa, D. (2013). A tutorial on sensitivity analyses in clinical trials: the what, why, when and how. BMC medical research methodology, 13(1), 92.

Weinstein, N., Deci, E. L., \& Ryan, R. M. (2011). Motivational determinants of integrating positive and negative past identities. Journal of personality and social psychology, 100(3), 527. Zenner, C., Herrnleben-Kurz, S., \& Walach, H. (2013). Mindfulness-based interventions in schools-a systematic review and meta-analysis. Frontiers in psychology, 5, 603-603. 
Table 1. Mindfulness-Based Intervention Session Content.

\section{Session Content}

1 Overview of class rules and participant presentations. Expectations and intentions in regards to the intervention. Introduction to mindful eating.

2 Body scan meditation. Introduction to components of emotions (thoughts, physical sensations, behaviour) and stress.

3 Breathing meditation. Introduction to sitting meditation. Mindful movements through yoga-like poses.

4 Breathing meditation. Introduction to concepts of acceptance of emotions.

$5 \quad$ Mindful check-in exercises. Mindfulness through the senses.

6 Breathing meditation with a special focus on thoughts and judgements. Group discussion on thoughts and judgements.

$7 \quad$ Walking meditation. Group discussion on self-care and acceptance.

8 Short sitting meditation. Group discussion on intentions set at first session. Feedback regarding intervention. Distribution of a pebble stone as a reminder of the experience. 
Table 2. Participant Demographics.

\begin{tabular}{lr}
\hline Participants (N) & 14 \\
Age & \\
M & 10.7 \\
SD & 1.1 \\
& \\
Gender (\%) & \\
Boys & $42.9 \%$ \\
Girls & $57.1 \%$ \\
\end{tabular}


18 C. Malboeuf-Hurtubise et al.

Table 3. Means, Standard Deviations and Results of Repeated-Measures ANOVA for the Need Satisfaction Scale.

\begin{tabular}{llllll}
\hline $\begin{array}{l}\text { Dependent } \\
\text { variable }\end{array}$ & Pre-test (M) & Post-test (M) & \multicolumn{3}{c}{ Overall model } \\
& & & & & \\
\cline { 2 - 6 } & & $5.00(0.27)$ & 6.85 & $.02 *$ & .35 \\
& & & & \\
\hline $\begin{array}{l}\text { Need satisfaction } \\
\text { (composite score) }\end{array}$ & $5.60(0.31)$ & $5.07(1.15)$ & 0.81 & .38 & .06 \\
Autonomy & $5.35(1.14)$ & $4.76(1.13)$ & 6.73 & $.02 *$ & .34 \\
Competence & $5.74(1.35)$ & $5.00(1.37)$ & 3.74 & .07 & .22 \\
Relatedness & $5.68(1.44)$ & & & & \\
\hline
\end{tabular}

$* p \leq \overline{0.05}$ 


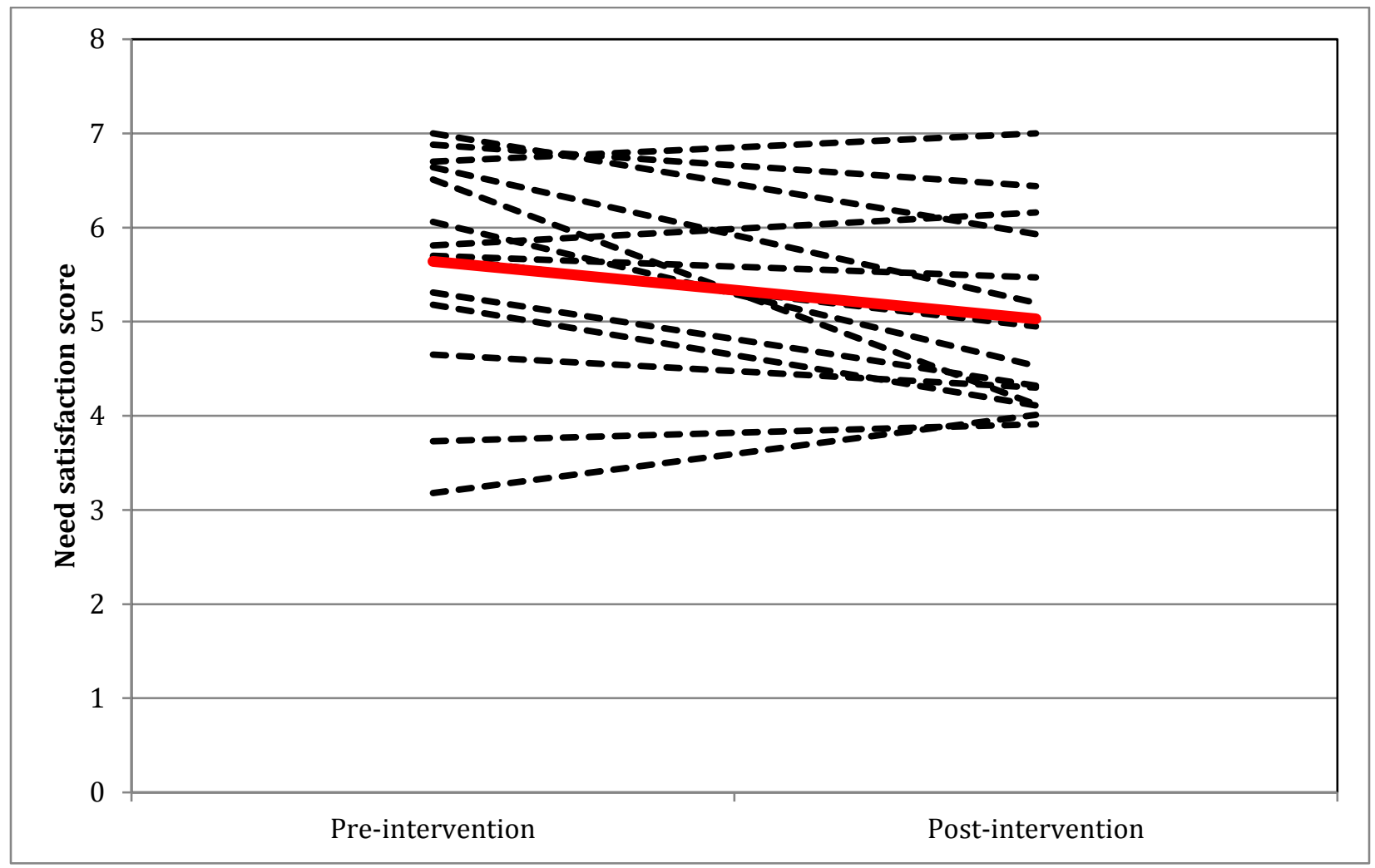

Figure 1. Individual Need Satisfaction Trajectories Pre-to-Post Intervention.

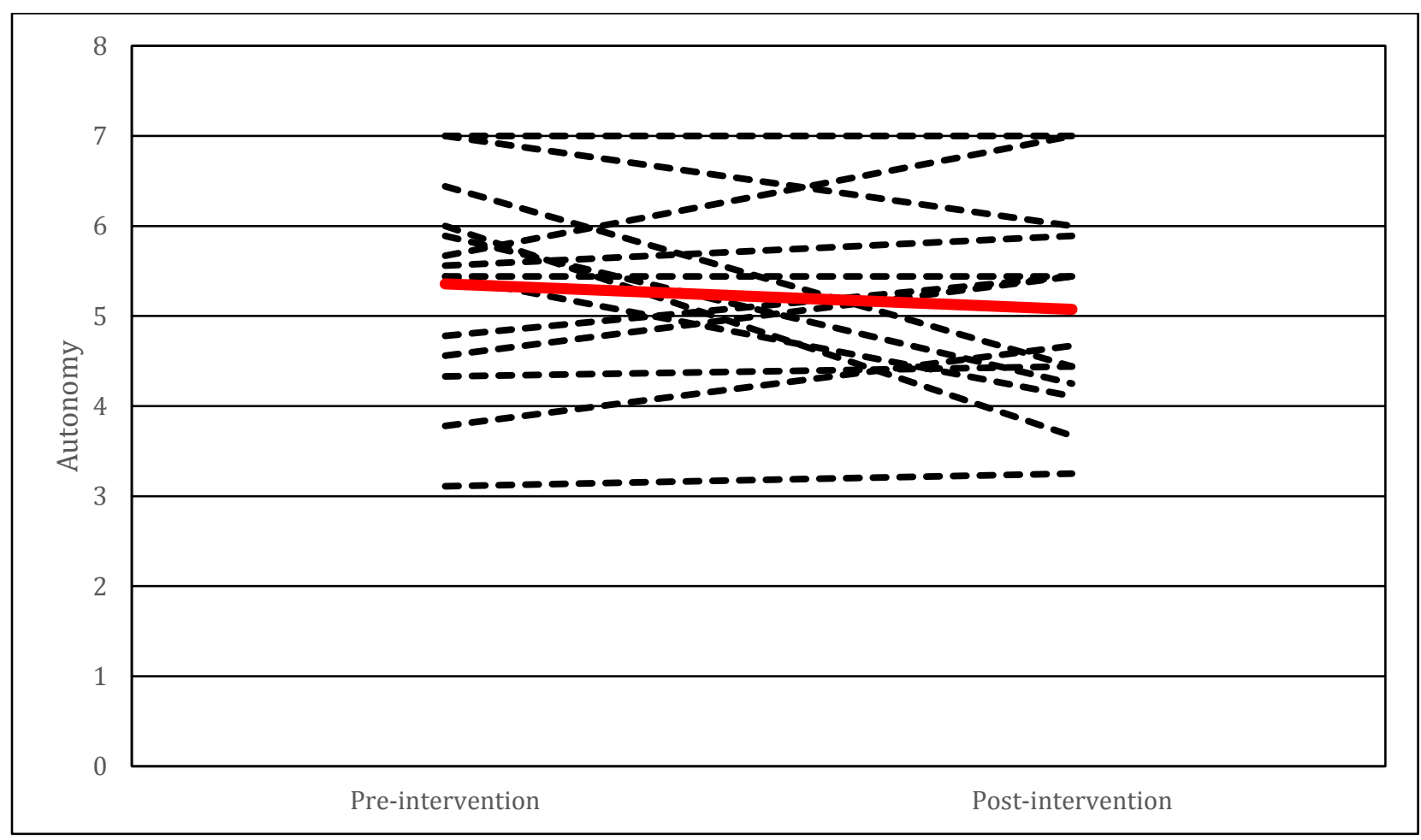

Figure 2. Individual Autonomy Trajectories Pre-to-Post Intervention. 


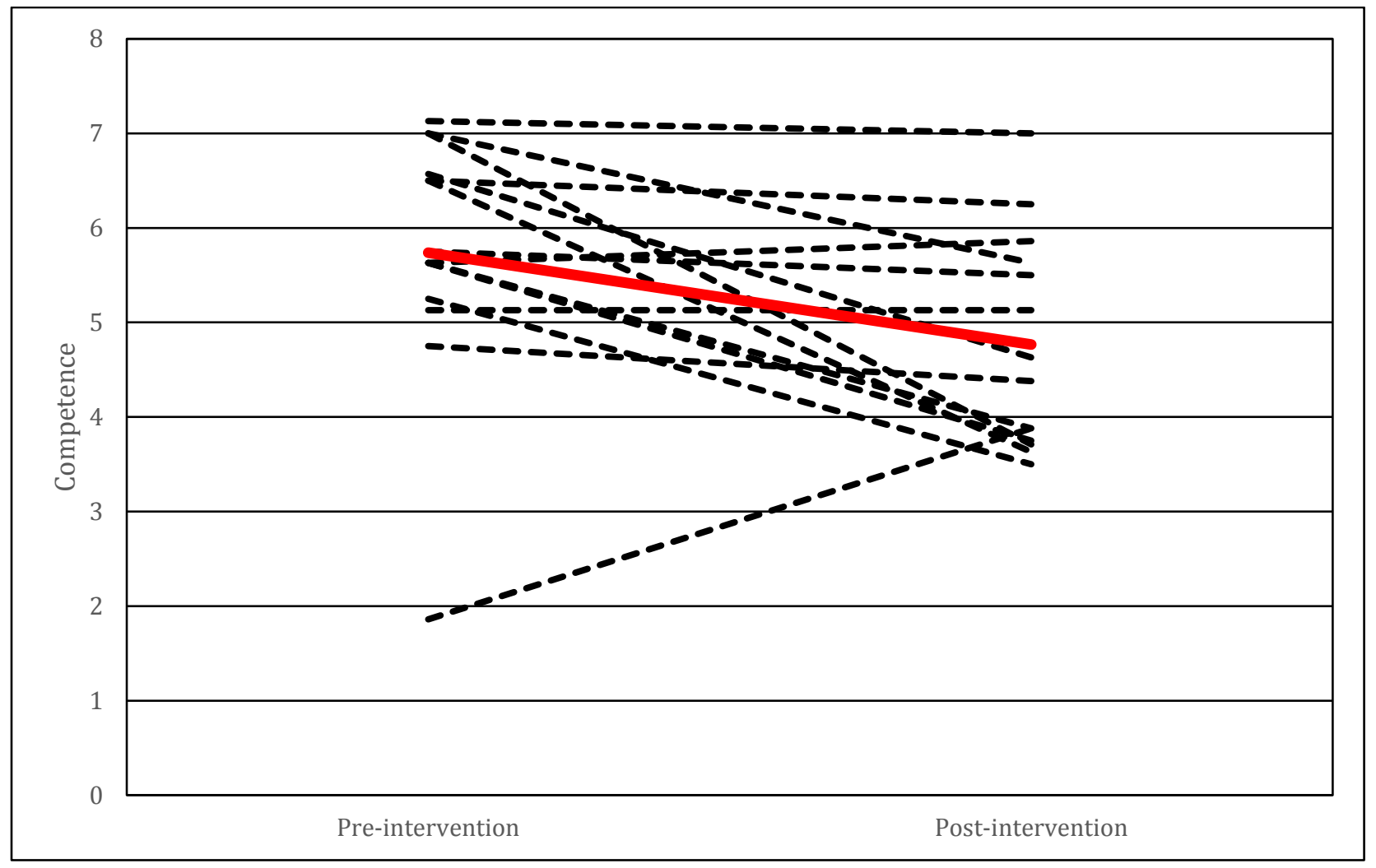

Figure 3. Individual Competence Trajectories Pre-to-Post Intervention.

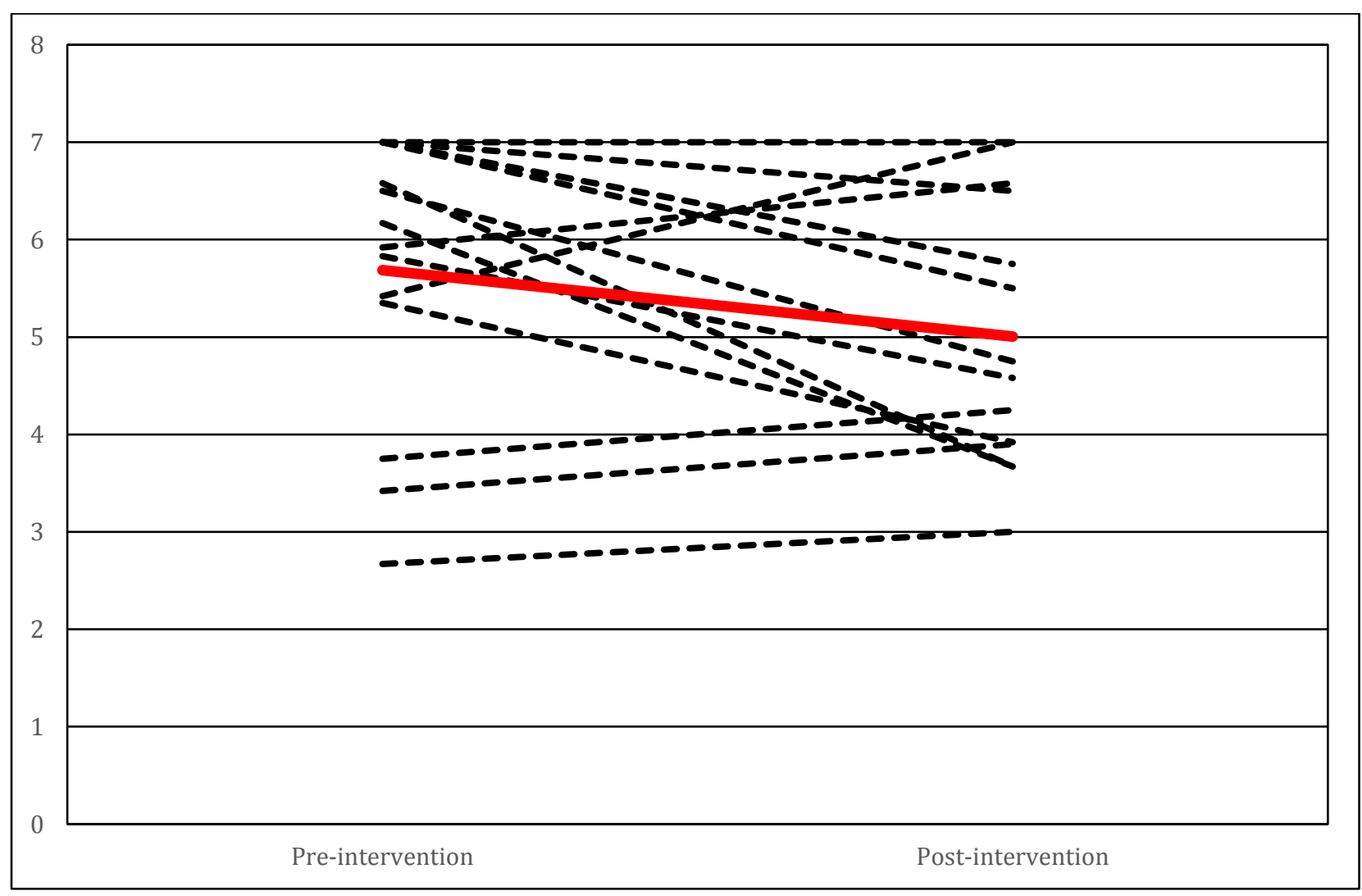

Figure 4. Individual Relatedness Trajectories Pre-to-Post Intervention. 